\title{
Restoration of learning in hepatic encephalopathy by pharmacological manipulation of cGMP levels in brain Vicente Felipo*
}

\author{
Address: Laboratory of Neurobiology, Centro de Investigacion Principe Felipe, Valencia, Spain \\ Email: Vicente Felipo* - vfelipo@cipf.es \\ * Corresponding author
}

from $3^{\text {rd }}$ International Conference on cGMP Generators, Effectors and Therapeutic Implications

Dresden, Germany. 15-17 June 2007

Published: 25 July 2007

BMC Pharmacology 2007, 7(SuppI I):SI3 doi:I0.I I86/I47I-22I 0-7-SI-SI3

This abstract is available from: http://www.biomedcentral.com/I47I-22 I0/7/SI/SI3

(c) 2007 Felipo; licensee BioMed Central Ltd.

Hepatic encephalopathy is a complex neuropsychiatric syndrome present in patients with liver disease that includes impaired intellectual function. Cognitive function and learning are impaired in patients with liver disease with overt or minimal hepatic encephalopathy and in animal models of chronic liver failure or hyperammonemia by mechanisms that remain unclear.

We have shown that chronic moderate hyperammonemia, similar to that present in patients with liver cirrhosis, interferes with signal transduction pathways associated to both ionotropic (NMDA) and metabotropic glutamate receptors. These alterations are responsible for some of the neurological alterations present in hepatic encephalopathy. Some of these studies are summarized in this presentation.

Activation of NMDA receptor increases intracellular calcium, which binds to calmodulin and activates nitric oxide synthase (NOS), increasing nitric oxide (NO), which activates guanylate cyclase and increases cyclic GMP (cGMP). We have shown by in vivo brain microdialysis that the function of this Glu-NO-cGMP pathway is impaired in brain in vivo in animal models of chronic liver failure (portacaval anastomosis or bile duct ligation) and of hyperammonemia without liver failure.

We administer NMDA through microdialysis probes to the rats and assess the activation of the Glu-NO-cGMP pathway by determining the increase in extracellular
cGMP induced by NMDA. The function of the pathway is impaired in cerebellum and cerebral cortex in vivo in rats with chronic liver failure, and this is due to hyperammonemia. The activation of guanylate cyclase by $\mathrm{NO}$ is also impaired in cerebellum and cerebral cortex in patients died with hepatic encephalopathy.

This glutamate-nitric oxide-cGMP pathway modulates some forms of learning and memory. We hypothesized that impairment of some forms of learning in liver failure and hyperammonemia would be the result of the impairment of the function of the pathway and that pharmacological manipulation of the pathway to increase cGMP content could restore learning ability. We have been able to restore learning ability in these rats modulating cGMP levels in brain by 3 different procedures:

a) continuous intracerebral administration, through mini-osmotic pumps, of zaprinast, an inhibitor of the phosphodiesterase that degrades CGMP; b) chronic intracerebral administration of cGMP; c) chronic oral administration of sildenafil, an inhibitor of the phosphodiesterase that crosses the blood-brain barrier. These results have allowed: a) to identify steps in glutamatergic neurotransmission altered in brain in vivo in animal models and in patients died in hepatic encephalopathy; b) to clarify some of the mechanisms leading to cognitive impairment; c) to restore learning ability in rats with hepatic encephalopathy. 
Using these animal models we have therefore identified a therapeutic target and pharmacological procedures to reverse one of the main neurological alteration in patients with hepatic encephalopathy.

Publish with Bio Med Central and every scientist can read your work free of charge

"BioMed Central will be the most significant development for disseminating the results of biomedical research in our lifetime. " Sir Paul Nurse, Cancer Research UK

Your research papers will be:

- available free of charge to the entire biomedical community

- peer reviewed and published immediately upon acceptance

- cited in PubMed and archived on PubMed Central

- yours - you keep the copyright 